\title{
Nebulized Albuterol Delivery in a Model of Spontaneously Breathing Children With Tracheostomy
}

\author{
Ariel Berlinski MD
}

\begin{abstract}
BACKGROUND: Nebulized therapy is commonly used in spontaneously breathing tracheostomized patients, despite a lack of recommended devices and techniques. I compared albuterol dose delivered to a model of spontaneously breathing children with tracheostomy, using different nebulizers, tracheostomy tube sizes, inhalation techniques, and breathing patterns. METHODS: A tracheostomy model was connected in series to a breathing simulator, with a filter interposed. I simulated the breathing patterns of a 16-month-old child and 12-year-old child, and tested tracheostomy tubes with internal diameters of $3.5 \mathrm{~mm}$ and $5.5 \mathrm{~mm}$. Albuterol nebulizer solution $(2.5 \mathrm{mg} / 3 \mathrm{~mL})$ was used. A breath-enhanced nebulizer (Pari LC Plus), a breath-actuated nebulizer (AeroEclipse), and a nebulizer that continuously delivers aerosol (Up-Draft II Opti-Neb) were operated for 5 min at $6 \mathrm{~L} / \mathrm{min}$ with wall air. The Up-Draft II was tested with T-piece and mask interfaces, with an extension tube, and with and without assisted breathing (every breath and every other breath). The amount of albuterol delivered was analyzed via spectrophotometry. Particle size distribution was measured with a cascade impactor. RESULTS: The Pari LC Plus was more efficient than the Up-Draft II or AeroEclipse. Assisted breathing with the Up-Draft II with extension increased albuterol delivery with every other breath (second best device/configuration), being superior to every breath technique. Adding an extension tube increased delivered albuterol. T-piece was more efficient than mask. Breathing patterns with larger tidal volume increased albuterol delivery. Tracheostomy size had less impact on drug delivery. Mass median aerodynamic diameter decreased by $48-74 \%$ when passing through the tracheostomy tubes, and $0.8 \%$ of the nominal dose was deposited in the tracheostomy tube. CONCLUSIONS: Albuterol delivery in a model of spontaneously breathing children with tracheostomy is influenced by type of device and configuration, use of assisted breathing, breathing pattern, and tracheostomy tube size. Mass median aerodynamic diameter significantly decreases during passage through a tracheostomy tube. Key words: tracheostomy; nebulizer; delivery device; children; albuterol. [Respir Care 2013;58(12):2076-2086. ( 2013 Daedalus Enterprises]
\end{abstract}

\section{Introduction}

Nebulized aerosols are frequently prescribed to spontaneously breathing tracheostomized children. A recent sur-

\footnotetext{
Dr Berlinski is affiliated with the Pulmonology Section, Department of Pediatrics, University of Arkansas for Medical Sciences, and with the Pediatric Aerosol Research Laboratory, Arkansas Children's Hospital Research Institute, Little Rock, Arkansas.
}

This research was partly supported by the University of Arkansas for Medical Sciences College of Medicine Children's University Medical Group Fund Grant Program. The Pediatric Aerosol Research Laboratory at Arkansas Children's Hospital Research Institute was partially established by and receives support from the George Endowment for Asthma. vey demonstrated a wide variability in devices and techniques used. ${ }^{1}$ Best practices guidelines are needed for the delivery of aerosols to spontaneously breathing tracheostomized children, but few data are available. ${ }^{2}$

Pressurized metered-dose inhalers (pMDIs), nebulizers, and dry powder inhalers have been adapted for aerosol

\footnotetext{
Dr Berlinski has disclosed relationships with Johnson \& Johnson, MPEX Pharmaceutical, Gilead, Philips, Genentech, Vertex, and S\&T Technologies.

Dr Berlinski presented a version of this paper at the 2011 meeting of the International Society for Aerosols in Medicine, held June 18-22, 2011, in Rotterdam, Netherlands.
} 
delivery through tracheostomy tubes. ${ }^{3-12}$ A few in vitro studies, mostly using adult models, have provided some information regarding the intricacies of delivering aerosol through an artificial airway. ${ }^{13-16}$ These studies showed that aerosol delivery is significantly affected by tracheostomy tube size, interface, type and configuration of add-on devices, use of assisted breathing, and bias flow. We previously reported that in a model of spontaneously breathing children with tracheostomy, assisted breathing reduced the delivered dose of pMDI aerosol. ${ }^{13}$ Those data were not in agreement with data obtained using an adult model with nebulized therapy. ${ }^{15}$ There are very few data on nebulized therapy in spontaneously breathing tracheostomized pediatric patients. Extrapolation from adult data to pediatric scenarios could result in either under-dosing or over-dosing.

In this in vitro study I compared the amount of nebulized albuterol delivered to a model of spontaneously breathing children with tracheostomy, using different nebulizers, techniques, tracheostomy tube sizes, and breathing patterns.

I hypothesized that: different devices would deliver different amounts of albuterol; assisted breathing would decrease the delivered albuterol; larger tracheostomy tube size would increase the delivered albuterol; a larger tidal volume $\left(\mathrm{V}_{\mathrm{T}}\right)$ would deliver a larger amount of albuterol than a smaller $\mathrm{V}_{\mathrm{T}}$; different interfaces would affect the delivered albuterol; and passage through a tracheostomy tube would alter the aerosol's characteristics.

\section{Methods}

\section{Tracheostomy Model}

A previously described tracheal model of a 6-year-old child was used. ${ }^{13}$ The model comprised an $8 \mathrm{~cm}$ height and $1.2 \mathrm{~cm}$ internal diameter plastic tube (trachea) with an upper filter holder with a one-way valve (Pari Respiratory Equipment, Midlothian, Virginia) and a lower filter. The latter was connected in series to a breathing simulator (Pari Compass, Munich, Germany). The breathing simulator is a piston pump that can be programmed to deliver a specified $\mathrm{V}_{\mathrm{T}}$, inspiratory time, and breathing frequency. The model was positioned horizontally to prevent gravitational dripping of aerosol onto the filters (Fig. 1). ${ }^{16} \mathrm{~A}$ circular incision was made $2 \mathrm{~cm}$ below the upper end of

Correspondence: Ariel Berlinski MD, Pulmonary Section, Department of Pediatrics, Arkansas Children's Hospital Research Institute, 1 Children's Way, Slot 512-17, Little Rock, Arkansas 72202.E-mail: BerlinskiAriel@ uams.edu.

DOI: $10.4187 /$ respcare.02419

\section{QUICK LOOK}

\section{Current knowledge}

Nebulized aerosols are frequently prescribed to spontaneously breathing tracheostomized children. A recent survey found wide variability in devices and techniques used.

\section{What this paper contributes to our knowledge}

The amount of albuterol delivered to a model of a spontaneously breathing tracheostomized pediatric patient was influenced by the type of aerosol device and its configuration, the use of assisted delivery, breathing pattern, and tracheostomy tube size. Aerosol particle size significantly decreased while passing through the tracheostomy tube.

the plastic tube to allow placement of the tracheostomy tube. The model allows bidirectional air flow through the tracheostomy tube and the trachea, and unidirectional flow (exhalation) through the upper filter.

\section{Tracheostomy Tubes}

Uncuffed tracheostomy tubes (Tracoe, Boston Medical Products, Westborough, Massachusetts) with internal/external diameters of $3.5 / 5 \mathrm{~mm}$, and 5.5/7.6 $\mathrm{mm}$ were used.

\section{Breathing Patterns}

Two different breathing patterns, corresponding to a 16-month-old ( $\mathrm{V}_{\mathrm{T}} 80 \mathrm{~mL}$, breathing frequency 30 breaths/ min, inspiratory/expiratory ratio $1: 3$ ), and a 12-year-old $\left(\mathrm{V}_{\mathrm{T}} 310 \mathrm{~mL}\right.$, breathing frequency 20 breaths/min, inspiratory/expiratory ratio $1: 2$ ) were used. I chose these patterns to allow a better comparison with previous research on pMDI aerosol. ${ }^{13}$ The chosen $\mathrm{V}_{\mathrm{T}}$ represent $7 \mathrm{~mL} / \mathrm{kg}$ for 16-month-old and 12-year-old male children with weights in the 50th percentile, based on the growth charts of the Centers for Disease Control and Prevention. However, patients with neuromuscular disease or decreased respiratory drive can present similar patterns at older ages.

\section{Devices, Interfaces, and Delivery Technique}

Four units of nebulizers with 3 different operating principles were studied: a nebulizer that continuously delivers aerosol (Up-Draft II Opti-Neb, Hudson RCI/Teleflex Medical, Research Triangle Park, North Carolina), a breathenhanced nebulizer (Pari LC Plus, Pari Respiratory Equipment, Midlothian, Virginia), and a breath-actuated 


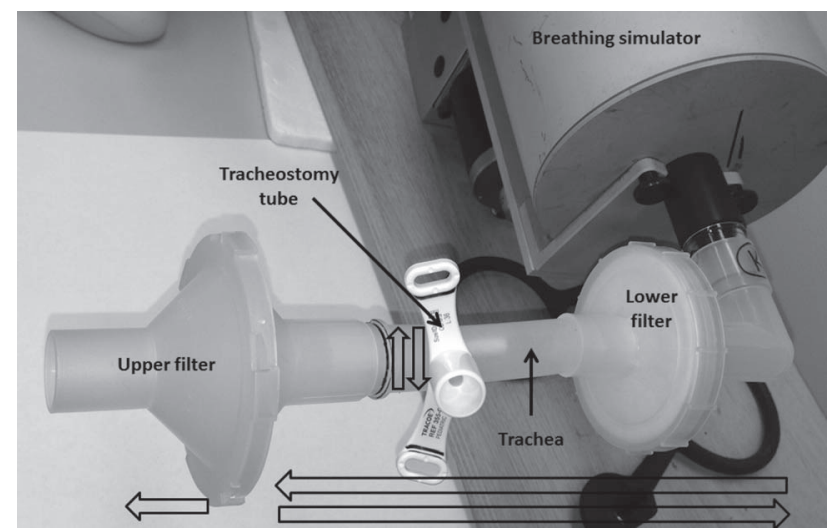

Fig. 1. Experimental setup to model nebulized albuterol delivery to a spontaneously breathing child with a tracheostomy. The hollow arrows represent the direction of air flow.

nebulizer (AeroEclipse II, Monaghan, Plattsburgh, New York). The Pari LC Plus has a one-way valve that allows air entrainment into the nebulizer during inhalation, therefore enhancing drug output. Aerosol is still released during exhalation in the Pari LC Plus. The AeroEclipse only releases aerosol during inhalation (breath-actuated mode). However, the AeroEclipse tested also has a continuous operation mode. The nebulizers were operated at $6 \mathrm{~L} / \mathrm{min}$ with wall air. The Pari LC Plus and AeroEclipse were only tested connected to the tracheostomy tube with an adapter (UltraSet, Smiths Medical, London, United Kingdom). The Up-Draft II was tested alone and with a $15 \mathrm{~cm}$ long, $22 \mathrm{~mm}$ diameter tube ( $110 \mathrm{~mL}$ volume) placed after the nebulizer. I also tested aerosol delivery with assisted breathing, at the beginning of either every other breath or every breath. The assisted breathing technique uses a resuscitation bag to enhance the inhaled volume and flow (Fig. 2). A selfinflating resuscitation bag (Pediatric AMBU Spur II, AMBU, Ballerup, Denmark) with a stroke volume of $450 \mathrm{~mL}$ was used. With the Up-Draft II, all configurations were tested with 2 different interfaces: T-piece and tracheostomy mask.

\section{Procedure}

Nebulizers were weighed dry, and after loading albuterol sulfate nebulizer solution $(2.5 \mathrm{mg} / 3 \mathrm{~mL})$. New disposable filters (Pari Respiratory Equipment, Midlothian, Virginia) were placed in both filter holders at the beginning of every procedure. A mass flow meter (model 4043, TSI, Shoreview, Minnesota) and its associated software were used to verify the accuracy of the $\mathrm{V}_{\mathrm{T}}$ delivered by the breathing simulator and wall gas flow. The nebulizer was connected to the gas source and tracheostomy model and operated for $5 \mathrm{~min}$. Upon completion, the nebulizer was re-weighed, then $5 \mathrm{~mL}$ of ultrapure water was added, then

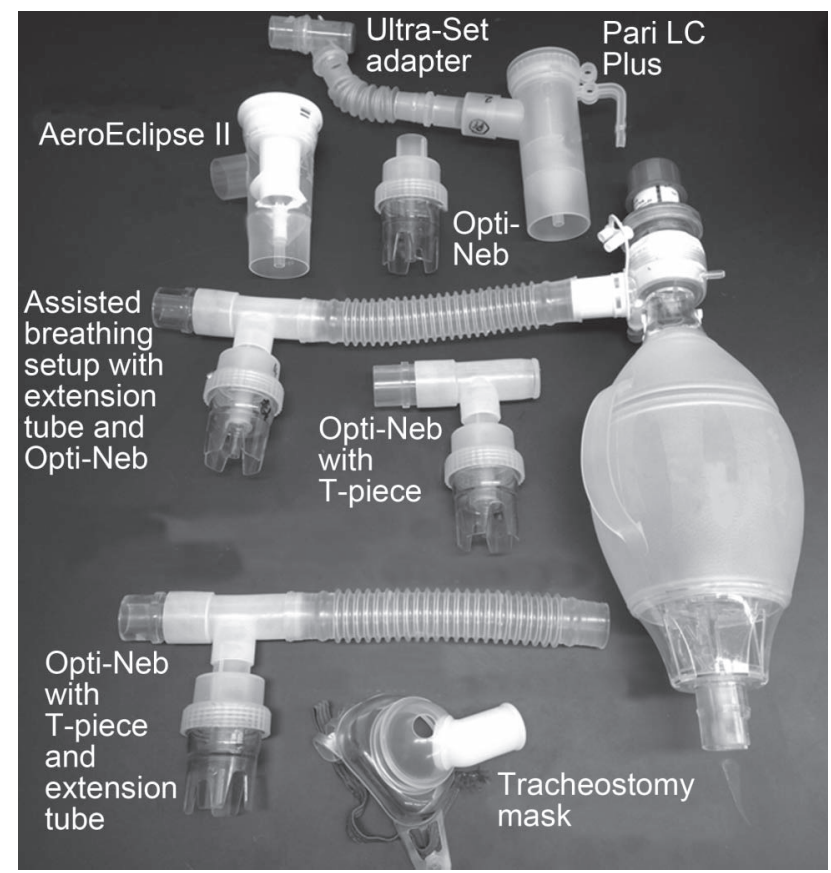

Fig. 2. Tested devices, interfaces, and adapters.

the nebulizer was weighed again The nebulizer was then swirled and the content was tested for albuterol concentration. The tracheal model was disassembled and the filters, filter holders, tracheostomy, and trachea were washed with ultrapure water and analyzed for albuterol concentration, via spectrophotometry at $276 \mathrm{~nm}$ (Biomate $3 \mathrm{UV}-\mathrm{V}$ is Spectrophotometer, Thermo Fisher Scientific, Waltham, Massachusetts). ${ }^{13}$

The amount of albuterol remaining in the nebulizer was calculated as follows:

(Weight with $5 \mathrm{~mL}$ ultrapure water - dry weight)

$$
\times \text { spectrophotometry concentration }
$$

This was calculated for each run to verify that drug output in fact happened in the occurrence of an extremely low delivered dose, but it was not reported.

\section{Study Design}

The 16-month-old breathing pattern with the $3.5 \mathrm{~mm}$ tracheostomy tube $(3.5 / 16 \mathrm{M})$, the 16 -month-old breathing pattern $/ 5.5 \mathrm{~mm}$ tracheostomy $(5.5 / 16 \mathrm{M})$, the 12 -year-old breathing pattern with the $3.5 \mathrm{~mm}$ tracheostomy tube (3.5/ $12 \mathrm{Y}$ ), and the 12-year-old breathing pattern with the $5.5 \mathrm{~mm}$ tracheostomy (5.5/12Y) were tested with the Pari LC Plus, AeroEclipse, and Up-Draft II. The Up-Draft II was tested in all combinations of configuration/interface/technique. 


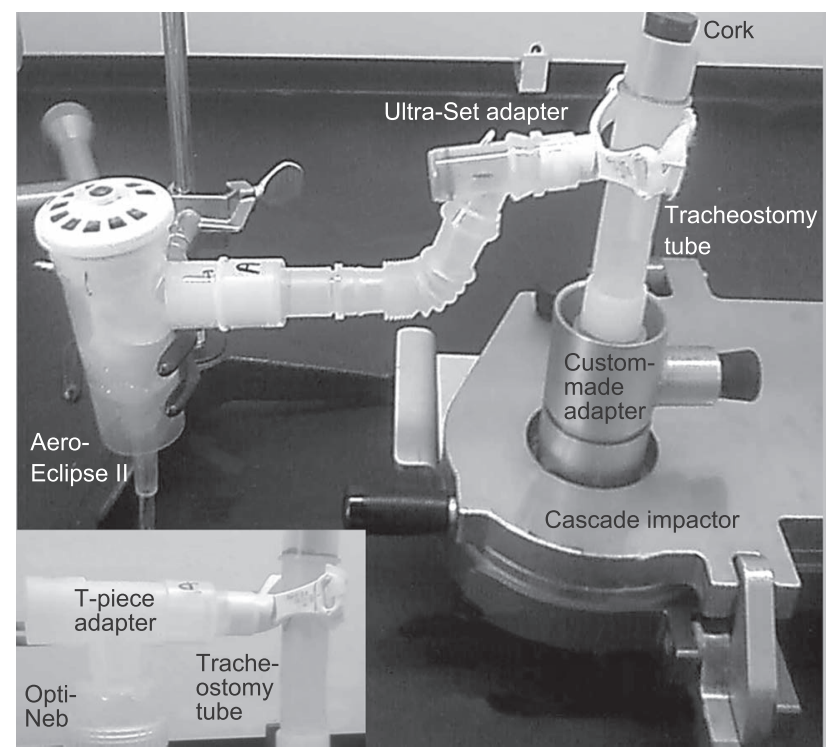

Fig. 3. Experimental setup to measure aerosol particle size distribution.

Four units of each nebulizer model were tested in each scenario.

\section{Particle Size Determination}

The Pari LC Plus and AeroEclipse were tested with their adapters. Only the Up-Draft II was tested with Tpiece and mask interfaces. The AeroEclipse was run in continuous operation mode. All 3 nebulizer models were tested with both tube sizes $(3.5 \mathrm{~mm}$ and $5.5 \mathrm{~mm})$. A cascade impactor (Next Generation Impactor, MSP, Shoreview, Minnesota) was used, with cooled technique, to measure the particle size of the aerosol leaving the tracheostomy tube. ${ }^{17}$ The configuration of the cascade impactor was changed to provide a more realistic measurement (Fig. 3). The United States Pharmacopeia throat was replaced by the tube used as trachea, with its upper end blocked by a cork, and the lower end was connected via a custom made adapter (MSP, Shoreview, Minnesota) to the body of the cascade impactor. The cascade impactor was calibrated (at $15 \mathrm{~L} / \mathrm{min}$ ), cooled for $90 \mathrm{~min}$, and used within 5 min of being removed from the refrigerator. All stages of the cascade impactor and the nebulizer were washed with ultrapure water and tested for albuterol concentration, via spectrophotometry, at $276 \mathrm{~nm}$. Mass median aerodynamic diameter (MMAD), geometric standard deviation (GSD), and percentage of particles $<5 \mu \mathrm{m}$ were calculated with inhaler testing data analysis software (CITDAS 3.1, Copley Scientific, Nottingham, United Kingdom), with the drug recovered from stage 2 to the external filter.

\section{Statistical Analysis}

Breathing simulation data were compared as delivery efficiency:

$$
(\mu \mathrm{g} \text { of albuterol captured } / 2,500 \mu \mathrm{g}) \times 100
$$

The following were used as outcome measures:

- Lower airways dose: drug delivered to the lower filter and filter holder

- Tracheal dose: drug delivered to the model trachea $(8 \mathrm{~cm} \times 1.2 \mathrm{~cm}$ plastic tube $)$

- Total patient dose: lower airways dose + tracheal dose

- Proximal/distal ratio: tracheal dose/lower airways dose

- Dose deposited in the tracheostomy tube

The lower airways dose represents aerosol that escaped deposition in the trachea. Inter-device comparison for each scenario (breathing pattern/tracheostomy size) was done with analysis of variance (ANOVA). Intra-device comparison for tracheostomy size and breathing pattern was done with ANOVA for repeated measures. The Tukey test was used when multiple comparison analysis was required. Two-way ANOVA was used to evaluate the effect of tracheostomy tube size and breathing pattern on albuterol delivery. Comparison of delivery techniques (assisted vs unassisted) was done with 2-tailed paired $t$ test. A statistical software package was used for data analysis (KaleidaGraph 4.1, Synergy Software, Reading, Pennsylvania). A $P$ value $<.05$ was considered statistically significant.

\section{Results}

\section{Lower Airways Dose}

Lower airways dose was higher for the Pari LC Plus than for either the Up-Draft II or the AeroEclipse, for all combinations of breathing pattern and tracheostomy size $(P<.001)$, and Up-Draft II was higher than AeroEclipse for all scenarios except 5.5/12Y $(P=.38)$ (Table 1).

The addition of an extension tube to the Up-Draft II/Tpiece setup increased lower airways dose only for the $3.5 /$ $16 \mathrm{M}$ scenario $(P=.03)$. No differences were noted for the Up-Draft II/mask setup $(P>.18)$.

Assisted breathing on every other breath with the UpDraft II/extension/T-piece setup increased lower airways dose in the $3.5 / 16 \mathrm{M}$ and $5.5 / 16 \mathrm{M}$ scenarios $(P=.007$ and $P=.01$, respectively). Assisted breathing on every other breath with the Up-Draft II/extension/mask increased lower airways dose in the $3.5 / 12 \mathrm{Y}$ and $5.5 / 12 \mathrm{Y}$ scenarios $(P=.03$ 
Table 1. Lower Airways Dose

\begin{tabular}{|c|c|c|c|c|}
\hline & \multicolumn{4}{|c|}{ Percentage of Nominal Dose } \\
\hline & $\begin{array}{c}\text { 16-Month-Old } \\
\text { Breathing Pattern } \\
\text { With } 3.5 \mathrm{~mm} \\
\text { Tracheostomy } \\
\text { Tube }\end{array}$ & $\begin{array}{c}\text { 12-Year-Old } \\
\text { Breathing Pattern } \\
\text { With } 3.5 \mathrm{~mm} \\
\text { Tracheostomy } \\
\text { Tube }\end{array}$ & $\begin{array}{l}\text { 16-Month-Old } \\
\text { Breathing Pattern } \\
\text { With } 5.5 \mathrm{~mm} \\
\text { Tracheostomy } \\
\text { Tube }\end{array}$ & $\begin{array}{c}\text { 12-Year-Old } \\
\text { Breathing Pattern } \\
\text { With } 5.5 \mathrm{~mm} \\
\text { Tracheostomy } \\
\text { Tube }\end{array}$ \\
\hline \multicolumn{5}{|l|}{ Device/scenario } \\
\hline Pari LC Plus (breath-enhanced) & $1.64 \pm 0.08$ & $2.63 \pm 0.28$ & $3.69 \pm 0.26$ & $5.19 \pm 0.36$ \\
\hline AeroEclipse (breath-actuated) & $0.15 \pm 0.08$ & $0.55 \pm 0.24$ & $0.58 \pm 0.23$ & $2.08 \pm 0.30$ \\
\hline \multicolumn{5}{|l|}{ Up-Draft II Opti-Neb (continuous aerosol delivery) } \\
\hline With T-piece interface & $0.99 \pm 0.13$ & $1.40 \pm 0.13$ & $1.09 \pm 0.07$ & $1.71 \pm 0.46$ \\
\hline $\begin{array}{l}\text { With T-piece interface plus extension tube } \\
\text { placed after the nebulizer }\end{array}$ & $1.57 \pm 0.33$ & $1.33 \pm 0.20$ & $1.32 \pm 0.21$ & $2.28 \pm 0.37$ \\
\hline $\begin{array}{l}\text { With T-piece interface plus extension tube } \\
\text { placed after the nebulizer and assisted } \\
\text { breathing on every other breath }\end{array}$ & $2.46 \pm 0.18$ & $3.04 \pm 0.21$ & $2.77 \pm 0.60$ & $2.83 \pm 0.91$ \\
\hline With mask interface & $1.71 \pm 0.11$ & $1.33 \pm 0.07$ & $1.02 \pm 0.43$ & $1.74 \pm 0.53$ \\
\hline $\begin{array}{l}\text { With mask interface plus extension tube placed } \\
\text { after the nebulizer }\end{array}$ & $1.88 \pm 0.28$ & $1.16 \pm 0.19$ & $0.96 \pm 0.24$ & $1.50 \pm 0.33$ \\
\hline $\begin{array}{l}\text { With mask interface plus extension tube placed } \\
\text { after the nebulizer and assisted breathing on } \\
\text { every other breath }\end{array}$ & $1.74 \pm 0.17$ & $1.74 \pm 0.34$ & $1.33 \pm 30$ & $2.18 \pm 0.18$ \\
\hline
\end{tabular}

and $P=.02$, respectively). Every-breath assisted breathing reduced the lower airways dose by $36 \%$ and $17 \%$ with the T-piece and mask interfaces, respectively, compared to every-other-breath assistance breathing.

With the Up-Draft II the mask interface increased lower airways dose only in the $3.5 / 16 \mathrm{M}$ scenario $(P=.002)$. However, when the extension tube was added, lower airways dose decreased in the $5.5 / 12 \mathrm{Y}$ scenario $(P=.02)$. With assisted breathing the lower airways dose decreased in the $3.5 / 16 \mathrm{M}$ and $5.5 / 16 \mathrm{M}$ scenario $(P=.001$ and $P=.01$, respectively).

Tracheostomy size and breathing pattern affected lower airways dose with the Pari LC Plus and the AeroEclipse $(P<.001$ for both), whereas only breathing pattern affected the Up-Draft II/T-piece setup $(P=.002)$. The interaction of both variables was significant only with the AeroEclipse $(P<.001)$. Assisted breathing with the UpDraft II removed the effect of the breathing pattern $(P=.40)$.

\section{Tracheal Dose}

Tracheal dose was higher with the Pari LC Plus than with the Up-Draft II or AeroEclipse, for all combinations of breathing pattern and tracheostomy size $(P<.001)$ (Table 2).

The addition of an extension tube to the Up-Draft II/Tpiece setup increased tracheal dose only in the 5.5/12Y scenario $(P=.01)$. No differences were noted for UpDraft II/mask $(P>.20)$.
With the Up-Draft II/extension/T-piece, every-otherbreath assisted breathing increased the tracheal dose in all combinations of breathing pattern and tracheostomy size except the $5.5 / 12$ Y scenario $(P=.06)$. This modality was similar to the Pari LC Plus for all scenarios except 5.5/12Y $(P=.01)$. With the Up-Draft II/extension/mask setup, every-other-breath assisted breathing increased the tracheal dose in the $3.5 / 12 \mathrm{Y}$ and $5.5 / 16 \mathrm{M}$ scenarios $(P=.048$ and $P=.049$, respectively). Every-breath assistance technique reduced the tracheal dose by $9 \%$ in the T-piece and mask interface scenarios, compared to every-other-breath assistance.

With the Up-Draft II, the mask interface increased the tracheal dose in the $3.5 / 16 \mathrm{M}$ scenario $(P=.005)$ and decreased tracheal dose in the 5.5/12Y scenario $(P=.02)$. When the extension tube was added to the Up-Draft II, tracheal dose increased in the $3.5 / 16 \mathrm{M}$ scenario $(P=.007)$ and decreased in the $3.5 / 12 \mathrm{Y}$ and $5.5 /$ $12 \mathrm{Y}$ scenarios $(P=.002$ and $P=.002$, respectively). With assisted breathing tracheal dose decreased in all combinations of breathing pattern and tracheostomy size $(P<.02)$.

Tracheostomy size and breathing pattern affected the tracheal dose with the AeroEclipse $(P=.02$ for both) but not with the Pari LC Plus $(P=.09$ and $P=.37$, respectively), whereas only breathing pattern affected the UpDraft II/T-piece setup $(P<.001)$. The interaction of both variables was significant only with the AeroEclipse $(P=.02)$. 
Table 2. Tracheal Dose

\begin{tabular}{|c|c|c|c|c|}
\hline & \multicolumn{4}{|c|}{ Percentage of Nominal Dose } \\
\hline & $\begin{array}{l}\text { 16-Month-Old } \\
\text { Breathing Pattern } \\
\text { With } 3.5 \mathrm{~mm} \\
\text { Tracheostomy } \\
\text { Tube }\end{array}$ & $\begin{array}{c}\text { 12-Year-Old } \\
\text { Breathing Pattern } \\
\text { With } 3.5 \mathrm{~mm} \\
\text { Tracheostomy } \\
\text { Tube }\end{array}$ & $\begin{array}{l}\text { 16-Month-Old } \\
\text { Breathing Pattern } \\
\text { With 5.5 mm } \\
\text { Tracheostomy } \\
\text { Tube }\end{array}$ & $\begin{array}{c}\text { 12-Year-Old } \\
\text { Breathing Pattern } \\
\text { With } 5.5 \mathrm{~mm} \\
\text { Tracheostomy } \\
\text { Tube }\end{array}$ \\
\hline \multicolumn{5}{|l|}{ Device/scenario } \\
\hline Pari LC Plus (breath-enhanced) & $10.51 \pm 0.97$ & $10.17 \pm 3.73$ & $7.10 \pm 1.72$ & $9.49 \pm 1.41$ \\
\hline AeroEclipse (breath-actuated) & $0.35 \pm 0.70$ & $0.32 \pm 0.39$ & $0.34 \pm 0.13$ & $1.57 \pm 0.41$ \\
\hline \multicolumn{5}{|l|}{ Up-Draft II Opti-Neb (continuous aerosol delivery) } \\
\hline With T-piece interface & $0.31 \pm 0.11$ & $1.81 \pm 0.27$ & $0.05 \pm 0.08$ & $1.77 \pm 0.28$ \\
\hline $\begin{array}{l}\text { With T-piece interface plus extension tube } \\
\text { placed after the nebulizer }\end{array}$ & $0.38 \pm 0.08$ & $1.95 \pm 0.00$ & $0.44 \pm 0.50$ & $3.11 \pm 0.71$ \\
\hline $\begin{array}{l}\text { With T-piece interface plus extension tube } \\
\text { placed after the nebulizer and assisted } \\
\text { breathing on every other breath }\end{array}$ & $8.53 \pm 1.36$ & $5.12 \pm 1.44$ & $5.77 \pm 0.68$ & $5.50 \pm 1.74$ \\
\hline With mask interface & $0.75 \pm 0.17$ & $1.40 \pm 0.64$ & $0.17 \pm 0.16$ & $1.13 \pm 0.29$ \\
\hline $\begin{array}{l}\text { With mask interface plus extension tube placed } \\
\text { after the nebulizer }\end{array}$ & $0.99 \pm 0.29$ & $1.13 \pm 0.32$ & $0.31 \pm 0.11$ & $1.09 \pm 0.36$ \\
\hline $\begin{array}{l}\text { With mask interface plus extension tube placed } \\
\text { after the nebulizer and assisted breathing on } \\
\text { every other breath }\end{array}$ & $0.82 \pm 0.13$ & $1.60 \pm 0.18$ & $0.14 \pm 0.07$ & $1.43 \pm 0.30$ \\
\hline
\end{tabular}

\section{Total Patient Dose}

Total patient dose was higher with the Pari LC Plus than with the Up-Draft II and AeroEclipse in all combinations of breathing pattern and tracheostomy size $(P<.001)$ (Fig. 4).

The addition of an extension tube to the Up-Draft II/Tpiece setup increased total patient dose in the $3.5 / 16 \mathrm{M}$ and

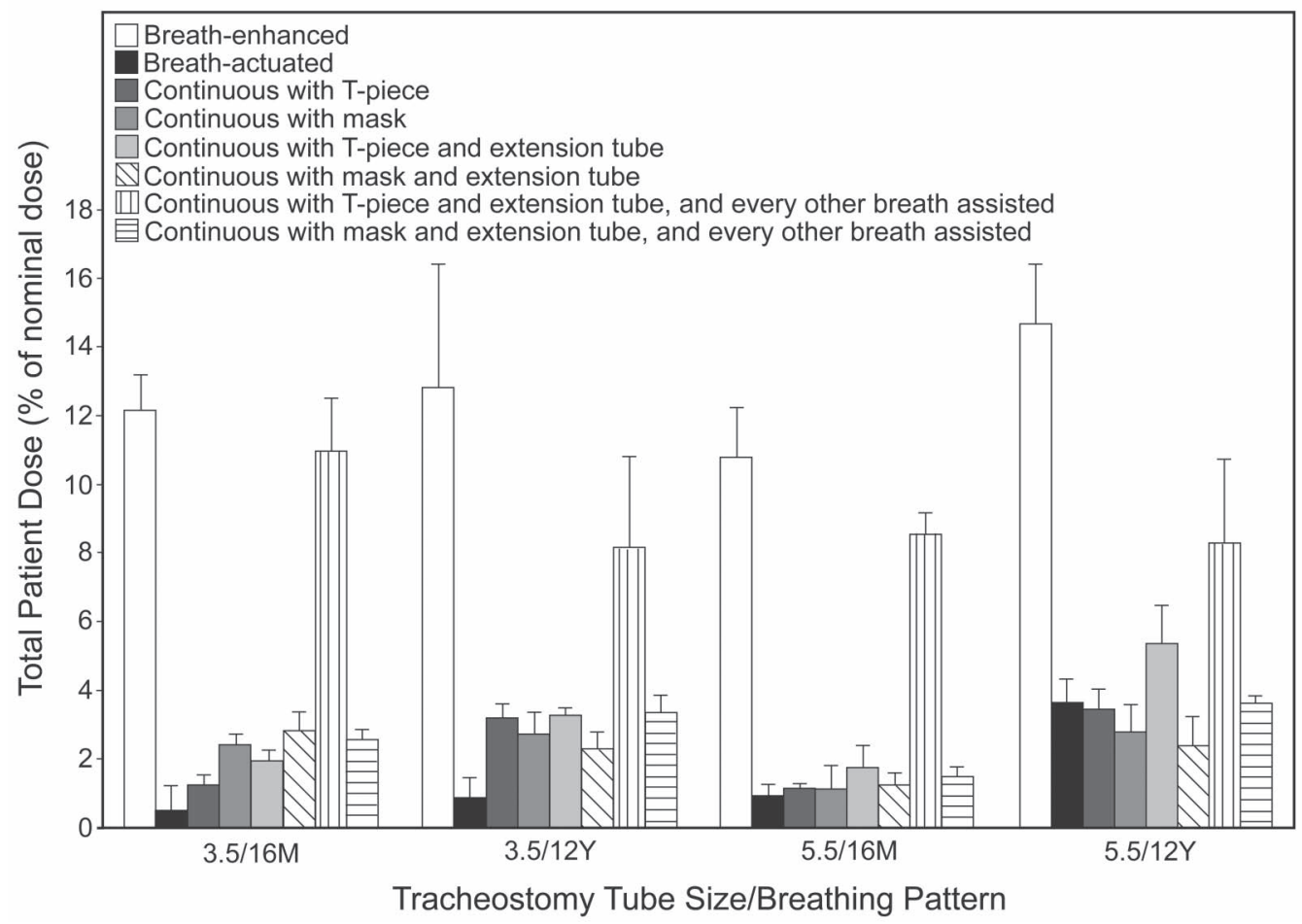

Fig. 4. Total patient dose, expressed as percentage of nominal dose. The X-axis labels are explained in the text. 


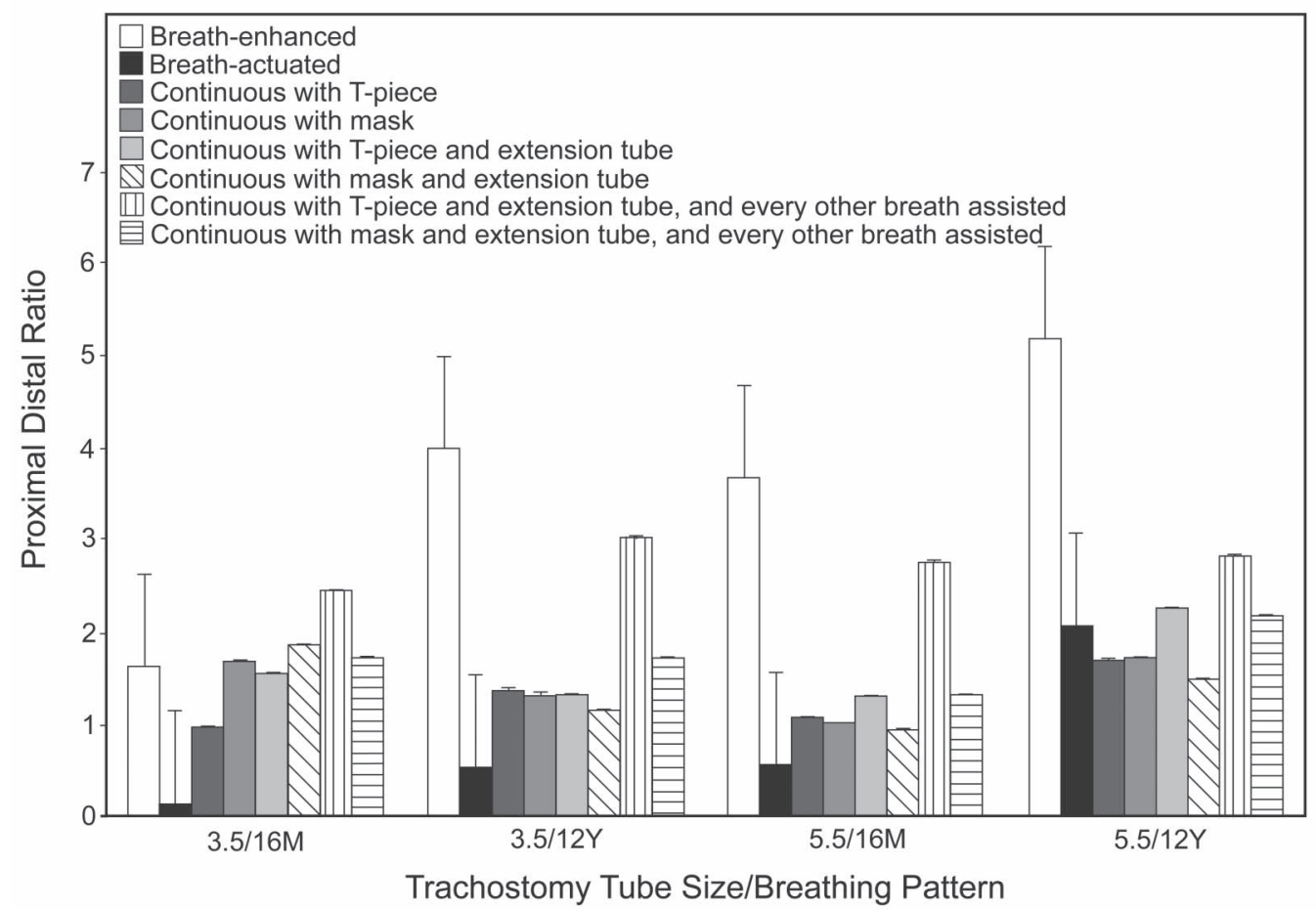

Fig. 5. Proximal/distal ratio. The X-axis labels are explained in the text.

5.5/12Y scenarios $(P=.02$ and $P=.03$, respectively $)$. No differences were noted for the Up-Draft II/mask setup $(P>.22)$.

Every-other-breath assisted breathing with the UpDraft II/extension/T-piece setup increased the total patient dose in all scenarios except 5.5/12Y $(P=.09)$. This modality was the second highest, and was similar to Pari LC Plus in the $3.5 / 16 \mathrm{M}$ scenario $(P=.25)$, but lower for other scenarios. Every-other-breath assisted breathing with the Up-Draft II/extension/mask increased total patient dose in the $3.5 / 12 \mathrm{Y}$ and $5.5 / 12 \mathrm{Y}$ scenarios $(P=.02$ and $P=.04$, respectively). Every-breath assistance reduced total patient dose by $7 \%$ and $24 \%$ with the T-piece and mask, respectively, compared to every-other-breath assistance.

With the Up-Draft II, the mask interface increased the total patient dose only in the $3.5 / 16 \mathrm{M}$ scenario $(P<.001)$. However, when the extension tube was added, total patient dose decreased in the $3.5 / 12 \mathrm{Y}$ and $5.5 / 12 \mathrm{Y}$ scenarios $(P=.02$ and $P=.042$, respectively), whereas the increase was maintained in the $3.5 / 16 \mathrm{M}$ scenario $(P=.03)$. Assisted breathing decreased the total patient dose in all the scenarios with the mask interface $(P<.03)$.

Breathing pattern affected total patient dose with the Up-Draft II, Pari LC Plus, and AeroEclipse $(P<.001$, $P=.002$, and $P=.003$, respectively). Tracheostomy size affected total patient dose with the AeroEclipse $(P<.001)$. Assisted breathing removed the effect of the breathing pattern with the Up-Draft II/T-piece setup $(P=.15)$, but not with the Up-Draft II/mask setup $(P<.001)$.

\section{Proximal/Distal Ratio}

The Pari LC Plus had a higher proximal/distal ratio than Up-Draft II or AeroEclipse in all combinations of breathing pattern and tracheostomy size except for Up-Draft II in the $3.5 / 12$ Y scenario $(P=.07)$ (Fig. 5).

The addition of an extension tube to the Up-Draft II setup increased the proximal/distal ratio only in the 5.5/ $16 \mathrm{M}$ scenario with mask interface $(P=.03)$.

Every-other-breath assisted breathing increased the prox$\mathrm{imal} /$ distal ratio in the $3.5 / 16 \mathrm{M}$ and $5.5 / 16 \mathrm{M}$ scenarios $(P<.001$ and $P=.004$, respectively) with the Up-Draft II/ extension/T-piece setup, but decreased the proximal/distal ratio in the $5.5 / 16 \mathrm{M}$ scenario $(P=.007)$ with the UpDraft II/extension/mask setup. The former had a proximal/ distal ratio similar to the Pari LC Plus, except in the 3.5/ $16 \mathrm{M}$ scenario $(P=.001)$.

The use of mask interface did not change the proximal/ distal ratio with the Up-Draft II alone. The addition of an extension tube increased the proximal/distal ratio in the $3.5 / 16 \mathrm{M}$ scenario $(P=.01)$, but decreased the proximal/ distal ratio in the $3.5 / 12 \mathrm{Y}$ and $5.5 / 12 \mathrm{Y}$ scenarios $(P=.01$ and $P=.003$, respectively). Assisted breathing decreased the proximal/distal ratio in all scenarios with the mask interface $(P<.006)$

Breathing pattern and tracheostomy size decreased the proximal/distal ratio with the Up-Draft II $(P<.001$ and $P=.02$, respectively) and the Pari LC Plus $(P=.03$ and $P<.001$, respectively), and had no effect with the 
Table 3. Particle Size Distribution of Nebulized Albuterol Exiting the Tracheostomy Tube

\begin{tabular}{|c|c|c|c|c|c|c|c|c|}
\hline \multirow[b]{3}{*}{ Tracheostomy tube size, $\mathrm{mm}$} & \multicolumn{4}{|c|}{$\begin{array}{c}\text { Up-Draft II Opti-Neb } \\
\text { (continuous aerosol delivery) }\end{array}$} & \multirow{2}{*}{\multicolumn{2}{|c|}{$\begin{array}{c}\text { Pari LC Plus } \\
\text { (breath-enhanced) }\end{array}$}} & \multirow{2}{*}{\multicolumn{2}{|c|}{$\begin{array}{c}\text { AeroEclipse } \\
\text { (breath-actuated) }\end{array}$}} \\
\hline & \multicolumn{2}{|c|}{ With T-Piece Interface } & \multicolumn{2}{|c|}{ With Mask } & & & & \\
\hline & 3.5 & 5.5 & 3.5 & 5.5 & 3.5 & 5.5 & 3.5 & 5.5 \\
\hline $\begin{array}{l}\text { Mass median aerodynamic diameter, } \\
\text { mean } \pm \mathrm{SD} \mu \mathrm{m}\end{array}$ & $1.20 \pm 0.12$ & $1.38 \pm 0.18$ & $1.43 \pm 0.12$ & $1.60 \pm 0.10$ & $1.26 \pm 0.18$ & $1.58 \pm 0.10$ & $1.22 \pm 0.15$ & $1.77 \pm 0.10$ \\
\hline Geometric standard deviation & $1.90 \pm 0.17$ & $1.85 \pm 0.06$ & $1.79 \pm 0.01$ & $1.93 \pm 0.07$ & $1.78 \pm 0.13$ & $1.77 \pm 0.04$ & $1.75 \pm 0.15$ & $1.68 \pm 0.07$ \\
\hline Percent of particles $<5 \mu \mathrm{m}$ & 100 & 99 & 100 & 99 & 99 & 99 & 100 & 99 \\
\hline
\end{tabular}

AeroEclipse $(P>.43)$. When an extension tube was added to the Up-Draft II/T-piece setup, the breathing pattern had a positive effect $(P<.001)$. When the Up-Draft II/mask setup was used instead, tracheostomy size exerted a negative effect $(P=.03)$, whereas breathing pattern exerted a positive one $(P=.001)$. With assisted breathing with the Up-Draft II/T-piece setup, breathing pattern and tracheostomy size exerted a negative effect $(P=.001$ and $P=.04$, respectively). When the mask interface was used instead, breathing pattern exerted a positive effect $(P<.001)$, whereas tracheostomy size had a negative one $(P<.001)$.

\section{Drug Deposited in the Tracheostomy Tube}

The median percentage of albuterol deposited in the tracheostomy tube was $0.8 \%$ (IQR $0.5-1 \%$ ) of the nominal dose.

\section{Particle Size}

The MMAD with the $3.5 \mathrm{~mm}$ tracheostomy tube ranged from $1.20 \pm 0.12 \mu \mathrm{m}$ (Up-Draft II/T-piece) to $1.43 \pm 0.12 \mu \mathrm{m}$ (Up-Draft II/mask) $(P=.13)$ (Table 3). The GSD with the $3.5 \mathrm{~mm}$ tracheostomy tube ranged from $1.75 \pm 0.15$ (AeroEclipse) to $1.90 \pm 0.17$ (Up-Draft II/ T-piece) $(P=.38)$. All the nebulizers had $99.9 \%$ of their particles smaller than $5 \mu \mathrm{m}(P>.99)$.

The MMAD with the $5.5 \mathrm{~mm}$ tracheostomy tube ranged from $1.38 \pm 0.18 \mu \mathrm{m}$ (Up-Draft II/T-piece) to $1.77 \pm 0.10 \mu \mathrm{m}$ (AeroEclipse) $(P<.001)$. Post hoc analysis showed that the difference was present only for the Up-Draft II/T-piece and AeroEclipse setups $(P=.04)$. The GSD with the $5.5 \mathrm{~mm}$ tracheostomy tube ranged from $1.68 \pm 0.07$ (AeroEclipse) to $1.93 \pm 0.07$ (Up-Draft II/ mask) $(P<.001)$. Post hoc analysis showed that UpDraft II/mask had a larger GSD than the AeroEclipse or Pari LC Plus $(P<.001$ and $P=.03$, respectively). All the nebulizers had $98.7-99.9 \%$ of their particles smaller than $5 \mu \mathrm{m}(P=.90)$.

When aerosol characteristics were compared between the $3.5 \mathrm{~mm}$ and the $5.5 \mathrm{~mm}$ tracheostomy tube, the following was noted:
- The MMAD with the $5.5 \mathrm{~mm}$ tube was larger for all the nebulizers except the Up-Draft II/T-piece setup $(P=.26)$, with an increase in size of $0.17 \mu \mathrm{m}(P=.01), 0.32 \mu \mathrm{m}$ $(P=.01)$, and $0.55 \mu \mathrm{m}(P=.01)$ with the Up-Draft II/ mask, Pari LC Plus, and AeroEclipse, respectively

- No differences were noted in their GSD $(P=.25)$

- No differences were noted in their percentage of particles $<5 \mu \mathrm{m}(P=10)$.

\section{Discussion}

The breath-enhanced nebulizer was the most efficient device, followed by the continuous-aerosol nebulizer with every-other-breath assisted breathing. Breathing pattern affected drug delivery more significantly than tracheostomy size, and T-piece was a more efficient interface than mask. The smaller tracheostomy tube, the younger-child breathing pattern, and assisted breathing caused more proximal aerosol deposition. Finally, aerosol particle size decreased after traveling through the tracheostomy tube, and little drug deposited in the tracheostomy tube.

\section{Delivery Device}

The finding that the different types of nebulizers resulted in different outcomes is in agreement with Pitance et al, ${ }^{16}$ who studied amikacin delivery in an adult tracheostomy (internal diameter $6.5-10 \mathrm{~mm})$ model $\left(\mathrm{V}_{\mathrm{T}} 440 \mathrm{~mL}\right.$, breathing frequency 20 breaths/min, inspiratory/expiratory ratio 1:2) with a collecting filter at the tip of the tracheostomy tube, creating a closed circuit. They tested a breathassisted nebulizer and a continuous-aerosol nebulizer alone and with an extension tube, and found that with the smallest internal diameter tested $(6.5 \mathrm{~mm})$ the continuous-aerosol nebulizer with extension tube had a slightly higher respiratory dose than the breath-assisted nebulizer. Their respiratory dose is equivalent to the total patient dose reported here. The other 2 reported studies tested only one type of nebulizer. ${ }^{14,15}$ The data reported here are consistent with reports on spontaneously breathing models, and sup- 
port the concept that data obtained with one operating type of nebulizer cannot be extrapolated to others. ${ }^{18}$

These data show that the Pari LC Plus delivered more drug proximally than distally. The Up-Draft II/T-piece/ extension setup with every-other-breath assistance performed similarly to the Pari LC Plus. This finding could be used to target the trachea for the delivery of antibiotics for treatment of tracheitis. The lower airways dose delivered by the Pari LC Plus and Up-Draft II/extension/T-piece with every-other-breath assistance was equivalent to 2-3 pMDI puffs $(90 \mu \mathrm{g} /$ puff) delivered with a non-electrostatic valved holding chamber in a similar model for all scenarios except $3.5 / 16 \mathrm{M}$ (range $3-5$ puffs). ${ }^{13}$ The poor performance of the AeroEclipse in this experimental setup could be partly due to the fact that the flows generated with the chosen breathing patterns were not large enough to activate and keep open the inhalation valve.

\section{Assisted Breathing}

Whether or not to use assisted breathing to deliver aerosol through a tracheostomy remains an important clinical question. These positive findings for the younger breathing pattern and all small tracheostomy sizes are in agreement with Ari et al, ${ }^{15}$ who used an adult type tracheostomy model (internal diameter $8 \mathrm{~mm})\left(\mathrm{V}_{\mathrm{T}} 450 \mathrm{~mL}\right.$, breathing frequency 20 breaths/min, inspiratory/expiratory ratio 1:2) and a continuous-aerosol jet nebulizer. Their model had a collecting filter connected at the end of the tracheostomy tube connected to a passive test lung. Their results are equivalent to the total patient dose reported here. This model prevented the buildup of pressure by allowing aerosol to be expired if it was not deposited on the filters, and also had a breathing simulator. These differences could explain the discrepancy in the magnitude of the improvement, with $55 \%$ in this study (5.5/12Y scenario) and $>300 \%$ in their study. The data reported here are not in agreement with the pMDI data obtained using the same model. ${ }^{13}$ Similar results were replicated in a follow-up study. ${ }^{19}$ The differences between the nebulizers and pMDIs could be partially explained by the fact that the nebulizers produce a slower aerosol, in a continuous fashion, that fills the model/airway with aerosol during exhalation. Conversely, a pMDI's aerosol plume production is intermittent and faster. I also found that every-other-breath assistance was superior to every-breath assistance. That difference might be due to the fact that every-other-breath assistance allows aerosol to collect in the reservoir in between breaths.

Assisted breathing increased the proximal/distal ratio with the younger breathing pattern. This could be due to the turbulence created by the gas coming from the resuscitation bag. This finding might be used to target the proximal airways during treatment of tracheitis.

\section{Extension Tube}

The enhancement in drug delivery found in some scenarios with the addition of an extension tube coupled to a T-piece is in agreement with Pitance et al. ${ }^{16}$ However, they reported a larger increase in delivered drug than reported here (12-22\% vs 53-54\%). The difference in magnitude of delivery improvement with the extension tube could be partly due to the difference in $\mathrm{V}_{\mathrm{T}}$ used. The volume of the extension tube is larger than the $\mathrm{V}_{\mathrm{T}}$ of the young child, so no entrainment of air without aerosol occurs.

\section{Interface}

The decrease in delivered dose when the patient interface was switched from T-piece to mask is in agreement with the findings of Ari et al ${ }^{15}$ and Piccuito et al. ${ }^{14}$ Ari et al reported a 50\% decrease and Piccuito et al reported a $15 \%$ decrease in an adult tracheostomy (internal diameter $8 \mathrm{~mm}$ ) model $\left(\mathrm{V}_{\mathrm{T}} 400 \mathrm{~mL}\right.$, breathing frequency 20 breaths $/ \mathrm{min}$, inspiratory/expiratory ratio $1: 2$ ) when switching from $\mathrm{T}$ piece to mask interface. ${ }^{14,15}$ Their experimental setups also had a filter at the end of the tube, so their data are comparable to the total patient dose reported here. ${ }^{14,15}$

\section{Tracheostomy Size}

The finding that tracheostomy size directly correlated with lower airways dose (AeroEclipse and Pari LC Plus) and with tracheal and total patient dose (AeroEclipse) is consistent with data reported for endotracheal tubes. ${ }^{20}$ Pitance et al, using an adult tracheostomy model, found a decrease in respiratory dose that ranged from $4 \%$ to $21 \%$ when changing from an internal diameter of $10 \mathrm{~mm}$ to $8.5 \mathrm{~mm}$, and from $17 \%$ to $31 \%$ when changing from an internal diameter of $8 \mathrm{~mm}$ to $6.5 \mathrm{~mm}$, using 3 devices. ${ }^{16}$ Their findings also showed that a decrement of internal diameter of tracheostomy tubes at smaller sizes results in more significant negative effect on the amount of delivered albuterol.

\section{Breathing Pattern}

The finding that the older-child breathing pattern increased the lower airways dose, tracheal, dose and total patient dose is in agreement with previously reported in vivo studies and with in vitro studies that used spontaneously breathing pediatric models. ${ }^{21,22} \mathrm{I}$ also found that assisted breathing removed the difference in patient dose among breathing patterns by significantly increasing lower airways dose (24-128\%) and total patient dose (55-465\%). This finding is the opposite of that reported for pMDIs using a similar model. ${ }^{13}$ I speculate that the differences between pMDI and nebulization could be due to the fact 
that nebulization provides a slower aerosol, generated at least during all the inspiratory time, and that the nominal dose is much higher $(2,500 \mu \mathrm{g}$ vs $90 \mu \mathrm{g})$.

When tracheal dose was analyzed, the same findings were noted except for the Pari LC Plus, which showed no differences across breathing patterns. Tracheal dose was 30-34-fold and 5-6-fold higher with the Pari LC Plus than with the Up-Draft II or AeroEclipse for the smallest tracheostomy with the younger-child breathing pattern and with the largest tracheostomy size and the older-child breathing pattern, respectively.

\section{Drug Deposited in the Tracheostomy Tube}

The low amount of drug deposited in the tracheostomy tube $(0.8 \%$ of nominal dose) contrasts with higher values reported with pMDIs, using either similar (7.8\%) or different (10\%) setups. ${ }^{13,23}$ These differences could be due to the higher velocity of the pMDI aerosol and impaction deposition on the tracheostomy tube wall. I found much lower tracheostomy tube deposition than did Pitance et al, using an adult model, who reported a range of $2-16 \%$ of the nominal dose. ${ }^{16}$ This might be due to differences in experimental setup. As noted above, aerosols did not have any escape, and buildup of pressure could have occurred resulting in more deposition in the tracheostomy tube.

\section{Particle Size}

The finding that aerosol particle size reduces when passing through a tracheostomy tube is in agreement with data obtained with radio-labeled aerosol passing through a $3.5 \mathrm{~mm}$ endotracheal tube. ${ }^{24,25}$ Arhens et al also reported an MMAD decrease, from $3.4 \mu \mathrm{m}$ at the mouth of a jet nebulizer to $1.2 \mu \mathrm{m}, 1 \mu \mathrm{m}$, and $0.48 \mu \mathrm{m}$ at the tips of endotracheal tubes with internal diameter of $3 \mathrm{~mm}, 6 \mathrm{~mm}$, and $9 \mathrm{~mm}$, respectively. ${ }^{20}$ The MMAD decreased by 48 $74 \%$ when passing through the tracheostomy tubes. The MMAD of the aerosol from the Up-Draft II decreased from $4.56 \mu \mathrm{m}$ to $1.2 \mu \mathrm{m}$ and $1.38 \mu \mathrm{m}$ after passing a $3.5 \mathrm{~mm}$ and $5.5 \mathrm{~mm}$ tube, respectively. ${ }^{17}$ The MMAD of the aerosol from the Pari LC Plus decreased from $3.47 \mu \mathrm{m}$ to $1.26 \mu \mathrm{m}$ and $1.58 \mu \mathrm{m}$ after passing a $3.5 \mathrm{~mm}$ and $5.5 \mathrm{~mm}$ tube, respectively. ${ }^{17}$ The MMAD of the aerosol from the AeroEclipse decreased from $3.43 \mu \mathrm{m}$ to $1.22 \mu \mathrm{m}$ and $1.77 \mu \mathrm{m}$ after passing a $3.5 \mathrm{~mm}$ and $5.5 \mathrm{~mm}$ tube, respectively. ${ }^{24}$ The reduction in particle size is most likely due to impaction of the larger droplets against the tracheostomy tube walls. Future studies should evaluate weather using aerosols with an MMAD of $1 \mu \mathrm{m}$ can improve delivery.

\section{Model}

The 2-compartment model used provides richer information than can a single-compartment model, which artificially increases the magnitude of certain phenomena. Arhens et al also reported that a 2-compartment model prevented the overestimation created by condensation in the tubes and subsequent dripping. ${ }^{20}$ In addition, a 2-compartment model resembles more what happens in human subjects. However, my model is not perfect because it does not allow air entrainment through the mouth or around the stoma. Future studies should include anatomically correct models to overcome the limitations noted above.

The in vitro nature of my study constitutes one of its main limitations. In particular, this setup overestimates the amount deposited in the lower airways, because once the drug is trapped on the filter, it cannot be exhaled. Another limitation is that I used only one size trachea. Despite these limitations, these data advance the present knowledge on how to optimize aerosol delivery to spontaneously breathing children with tracheostomy.

\section{Clinical Implications}

Drug delivery was low in most of the scenarios and device/delivery techniques studied. Assisted breathing with continuous aerosol nebulization improved delivery, and it should be considered, especially when the trachea is the targeted area. This setup was as efficient as the breathenhanced nebulizer setup, making the former the device of choice. Breath-actuated nebulizer should not be used unless opening of the valve by the patient is documented.

The best way of using these and other data and to be able to determine the applicability to a specific patient is by measuring the spontaneous $\mathrm{V}_{\mathrm{T}}$ through the tracheostomy with a Wright manometer. ${ }^{1,13}$

\section{Conclusions}

The breath-enhanced nebulizer was the most effective device. Every-other-breath assisted breathing increased aerosol delivery (second best), being superior to everybreath assisted breathing. Tracheostomy size and breathing pattern significantly affected drug delivery. T-piece was a more efficient interface. Aerosols changed their characteristics when traveling through tracheostomy tubes. The smaller tracheostomy tube, the younger-child breathing pattern, and assisted breathing cause more proximal aerosol deposition. These data underscore that extrapolation from different devices and different scenarios might lead to erroneous conclusions. 


\section{REFERENCES}

1. Willis D, Berlinski A. Survey of aerosol delivery techniques to spontaneously breathing tracheostomized children. Respir Care 2012; 57(8)1234-1241.

2. Amirav I, Newhouse MT. Aerosol therapy in tracheotomized children: time for guidelines! Respir Care 2012;57(8):1350.

3. O'Callaghan C, Dryden S, Cert DN, Gibbin K. Asthma therapy and a tracheostomy. J Laryngol Otol 1989;103(4):427-428.

4. Subhedar NV, Doyle C, Shaw NJ. Administration of inhaled medication via a tracheostomy in infants with chronic lung disease of prematurity. Pediatr Rehabil 1999;3(2):41-42.

5. Monksfield P. Modification of a spacer device for paediatric tracheostomy. Clin Otolaryngol 2008;33(2):193-194.

6. Webber PA, Brown AR. The use of a conical spacer after laryngectomy. BMJ (Clin Res Ed) 1984;288(6429):1537.

7. Nakhla V. A homemade modification of a spacer device for delivery of bronchodilator or steroid therapy in patients with tracheostomies. J Laryngol Otol 1997;111(4):363-365.

8. Mirza S, Hopkinson L, Malik TH, Willatt DJ. The use of inhalers in patients with tracheal stomas or tracheostomy tubes. J Laryngol Otol 1999;113(8):762-764.

9. Meeker DP, Stelmach K. Modification of the spacer device. Chest 1992;102(4):1243-1244.

10. García Pachón E, Casan P, Sanchís J. [Bronchodilators through tracheostomy]. Med Clin (Barc) 1992;99(10):396-397. Article in Spanish

11. Newhouse MT. Hemoptysis due to MDI therapy in a patient with permanent tracheostomy: treatment with mask AeroChamber. Chest 1999;115(1):279-282.

12. Nandapalan V, Currey M, Jones TM. A modified spacer device for inhalational drug therapy for chronic bronchitis/asthma in laryngectomised patients. Clin Otolaryngol 2000;25(2):118-119.

13. Berlinski A, Chavez A. Albuterol delivery via metered dose inhaler in a spontaneously breathing pediatric tracheostomy model. Pediatric Pulmonology 2013;48(10):1026-1034.

14. Piccuito CM, Hess DR. Albuterol delivery via tracheostomy tube. Respir Care 2005;50(8):1071-1076.
15. Ari A, Harwood R, Sheard M, Fink JB. An in-vitro evaluation of aerosol delivery through tracheostomy and endotracheal tubes using different interfaces. Respir Care 2012;57(7):1066-1070.

16. Pitance 1, Vecellio L, Delval G, Reychler G, Reychler H, Liistro G. Aerosol delivery through tracheostomy tubes: an in-vitro study. J Aerosol Med Pulm Drug Deliv 2013;26(2):76-83.

17. Berlinski A, Hayden JB. Optimization of a procedure used to measure aerosol characteristics of nebulized solutions using a cooled next generation impactor. J Aerosol Med Pulm Drug Deliv 2010,23(6)397-404.

18. Barry PW, O'Callahan C. An in-vitro analysis of the output of salbutamol from different nebulizers. Eur Respir Care 1999;13(5): 1164-1169.

19. Chavez A, Holt S, Heulitt M, Berlinski A. Albuterol delivery via $\mathrm{mdi} /$ spacer in a spontaneously breathing pediatric tracheostomy model: does bagging improve drug delivery? (abstract) Am J Respir Crit Care Med 2011;183(Suppl):A3383.

20. Ahrens RC, Ries RA, Popendorf W, Wiese JA. The delivery of therapeutic aerosols through endotracheal tubes. Pediatr Pulmonol 1986;2(1):19-26.

21. Chavez A, McCraken A, Berlinski A. Effect of face mask static dead volume, respiratory rate and tidal volume on inhaled albuterol delivery. Pediatr Pulmonol 2010;45(3):224-229.

22. Chua HL, Collis GG, Newbury AM, Chan K, Bower GD, Sly PD, Le Souef PN. The influence of age on aerosol deposition in children with cystic fibrosis. Eur Respir J 1994;7(12):185-191.

23. O'Riordan TG, Palmer LB, Smaldone GC. Aerosol deposition in mechanically ventilated patients. Optimizing nebulizer delivery. Am J Respir Crit Care Med 1994;149(1):214-219.

24. Berlinski A, Hayden J. Aerosol characteristics of $7 \%$ nebulized hypertonic saline delivered by 4 different nebulizers. Pediatr Pulmonol 2011;34(Suppl):336.

25. Fok TF, Al-Essa M, Monkman S, Dolovich M, Girard L, Coates G, Kirpalani H. Pulmonary deposition of salbutamol aerosol delivered by metered dose inhaler, jet nebulizer, and ultrasonic nebulizer in mechanically ventilated rabbits. Pediatr Res 1997;42(5):721-727. 